\title{
The Use Of Peer Tutoring To Improve The Passing Rates In Mathematics Placement Exams Of Engineering Students: A Success Story
}

Rolando García, Universidad del Turabo, Puerto Rico, USA Juan C. Morales, Universidad del Turabo, Puerto Rico, USA

Gloribel Rivera, Universidad del Turabo, Puerto Rico, USA

\begin{abstract}
This paper describes a highly successful peer tutoring program that has resulted in an improvement in the passing rates of mathematics placement exams from $16 \%$ to $42 \%$, on average. Statistical analyses were conducted using a Chi-Squared $\left(X^{2}\right)$ test for independence and the results were statistically significant ( $p$-value much less than 0.05). These encouraging results suggest that this type of initiative should be institutionalized at the end of the grant period that funds it. The paper describes the structure of the program, the conditions of the university in which it is being implemented, the details of the statistical analyses, and its impact in engineering education. This model may easily be replicated in academic institutions with similar conditions.
\end{abstract}

Keywords: Peer Tutoring; Mathematics; Engineering Education

\section{INTRODUCTION}

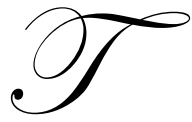

he spark that ignited this effort was the realization that placement exams provide a unique opportunity for first-year students to quickly advance in the sequence of mathematics courses that is required of any engineering curricula. Tutoring is offered at all levels of Algebra (considered remedial) as well as for Pre-Calculus II (trigonometry) and Calculus I which are the first two engineering-level courses. The virtues of this program, which is offered in the summer previous to starting the first year of college, are the following:

1. The student quickly progresses along the mathematics critical path. Each placement exam accelerates the potential graduation date by one semester. The student benefits by an earlier graduation date and the university benefits by improving the graduation rates in engineering.

2. For students who require tutoring at the most remedial of levels, the placement exams solve a critical problem in course scheduling. Most engineering courses, as well as the natural sciences component, have Calculus I as a prerequisite. If two or three semesters are required to come up to speed, the student will deplete all the possible courses that they can register for. Their academic load reduces to a single mathematics course. This situation is not favorable for anyone.

3. Many of the students that highly benefited from the summer mathematics tutoring program (SMTP) had already been exposed to part of the material covered during the tutoring sessions, even though it did not reflected as such in the mathematics scores of their college entry exam. Because of this, the students might lose interest during their first semester mathematics course since they are not placed correctly.

4. The student saves money since the tutoring services and the placement exams are free for them. In addition, they do not have to pay the registration fee for the courses as they would if they registered for them during the semester. The SMPT serves as mitigation tool for the change in the paradigm of how to finance their college tuition as a result of the changes in Pell grant regulations. 
5. It is offered during the summer when students have the time to immerse themselves in the SMPT and the placement exams. This provides an excellent opportunity for proactive students to empower themselves and take an active role in their immediate academic future.

6. Students that participate in the SMPT do so out of their own free will. The fact that a student chooses to participate in this effort, instead of idling during the summer, creates a very positive attitude in the student. This attitude will serve the student very well once they start the rigor of the engineering curriculum.

7. This program offers, in many cases, new engineering students their first exposure to a college-level instructional and educational setting, as it helps lay the initial framework needed to succeed in a demanding academic career.

Recognizing the importance and potential benefits that the placement exams might have on these students' academic career, a peer-tutoring program was developed. This approach was selected instead of a regular tutoring sessions or teacher-based class because the benefits of peer-tutoring throughout STEM (science, technology, engineering, and mathematics) careers are well documented, particularly in remedial courses (Bowen, et al., 2007; Newman-Ford, et al., 2007). From the literature review executed by Henderson, Fadali, \& Johnson (2002), they concluded that peer tutoring has a positive effect on student achievement and retention. Also, from their own research, they observed that students generally show a positive attitude towards tutoring. A study developed by Magin \& Churches (1995) concluded that the use of peer tutoring in engineering is an useful, viable teaching strategy for achieving course goals. Multiple case studies (Chen \& Liu, 2011; Luca \& Clarkson, 2002) have shown the positive impact that tutoring provides on the tutee performance. Also, Power \& Dunphy (2010) describe the peer tutoring environment as a "safe and non-threatening interactive learning situation". This favorable setting promotes student engagement which is critical in their first college year. Several studies point to the fact that engagement for first year college students is critical in successfully retaining them in STEM related fields (Knight, et al., 2003; Krause and Coates, 2008; Tinto, 2006).

This sort of activity also exposes students to a different learning scenario while providing them with an opportunity in which their effort could be rewarded rather quickly, since they can pass one or more placement exams during summer. Students that are willing to invest time of their summer vacation into this type of activity are showing compromise towards their college career and a willingness to improve themselves. These experiences have been shown to be important aspects in the learning process (Farkas, 2003). Boud, Cohen \& Sampson (2001) mention multiple benefits besides grade improvement that peer-tutoring programs provide, such as improvement of skills related to working with others and self-management skills utilized in the learning process.

There is an additional advantage obtained from this teaching strategy, which is the deeper learning of concepts obtained by the tutors. Beasley (1997) and Davis \& Wilcock (2004) point out the benefits that peertutoring sessions, whether they are formal or informal, provide for tutors themselves, making it a valuable experience for the tutor's personal and professional development. When peer tutoring works, two students benefit simultaneously from the process. Therefore, student tutors can, in fact, learn from their teaching experiences (Roscoe \& Chi, 2008). Atkinson et al. (2003) argue that the tutors' necessity to use examples to demonstrate important concepts and processes improves the self-learning process, as research on learning from worked-out examples has shown that they gain a deeper understanding by dissecting examples into steps and associating them to fundamental principles.

Therefore, the peer-tutoring approach for improving the student's performance before taking placement exams seems appropriate.

\section{ABOUT THE UNIVERSITY}

Universidad del Turabo (UT) is part of the Ana G. Méndez University System (AGMUS), one of the largest private university systems in Puerto Rico. The vision statements of all the engineering programs (to become the first choice for all motivated students who wish to pursue an engineering education) stem from the ideals of the founder of AGMUS, the late Ms. Ana G. Méndez. She initiated the AGMUS educational system 65 years ago as a means for Puerto Rican youth who, although capable and motivated, lacked the necessary skills required to continue university-level studies. In many cases these students were, and still are, the first generation in their families to 
attend a university. Ms. Ana G. Méndez opened the doors of opportunity to this segment of the population. The word "all" in the vision statement indicates that, while keeping the spirit of opportunity that inspired Ana G. Méndez, the engineering programs are not limited by it. The School of Engineering (SoE) strives to attract highly skilled students, which is done primarily through very competitive scholarships. The word "motivated" is also important as the students, once admitted, are put through the rigor of an engineering curriculum regardless of their background. Thus, although opportunity is provided to enter the UT SoE, only motivated students will be able to endure the curriculum. Realizing that the potential students that are interested in studying engineering will have variable backgrounds, the UT SoE decided to implement the SMTP described in this paper to provide better tools and opportunities to its freshmen.

\section{STRUCTURE OF THE TUTORING PROGRAM}

The SMTP began during the 2012 summer, as an initiative to tackle a long-standing situation. It started intertwined with the ongoing semester tutoring service in May 2012, during the last weeks of the semester. The semester tutoring program had tutors available from 9:00 am through 9:00 pm from Monday to Thursday and from 9:00 am through 5:00 pm on Fridays, servicing the students of the School of Engineering (SoE). The SoE students were required to reach out to the tutors during their work schedule or through email for scheduling appointments. This methodology, although successfully implemented within the students of the SoE, proved to be a challenge for high school students. They were not ready to participate in this kind of process because they lacked the discipline and structure to study by themselves, bring specific doubts to the tutors, and to schedule appointments. Realizing this, efforts where focused to develop a tutoring program specific to work with the needs of this group.

Two tutors, seniors in the SoE, were hired specifically for tutoring these students during the 2012 summer months. Because of time constraints and Human Resource regulations, only one tutor was supposed to be working at a time. Regardless of this, both tutors where present most of the time because of their willingness to help. One computer laboratory, with capacity for seating up to 30 students, was dedicated for the mathematics tutoring sessions. It was open from 9:00 am to 4:00 pm from Monday to Friday during six weeks of summer, and students were free to come during this period to better accommodate their schedules. The tutoring sessions utilized the Educosoft ${ }^{\odot}$ online platform (also used in UT Mathematics courses), which was provided by the Mathematics Department, free of charge. Independent study sessions took place under the supervision and tutelage of the two tutors. Approximately, 8 students were assisted daily, with some days reaching up to 15 students simultaneously. Students usually visited the SMTP for various days before taking the placement exam.

Halfway during the summer tutoring sessions, both tutors identified that most of the students were lacking important concepts that hindered their progression and that many of them shared the same challenges. This situation prompted the evolution of the tutoring program, as tutors started teaching short classes on the topics that students were having the most difficulties with. These classes were improvised on the spot and were not structured, but proved to be productive because most of the students took advantage of them. During the last two weeks of the SMTP, more than three mini classes were being taught on a daily basis, with most of the students that were present participating in them.

In the closure meeting of the SMTP, the tutors themselves brought to our attention that most of the students that assisted to the tutoring sessions needed classes and remedial work, not just individual study sessions with support. They suggested that the next iteration of the program should include a more a course-like component to tackle most of the subjects that students were having problems with. Also, the evaluation forms that students filled out after the tutoring sessions pointed out their interests in a more traditional, class-like approach for the SMTP.

During the next year, efforts were made to meet the challenge of developing an intensive remedial class that could be taught during one week of summer. This class should be able to help students achieve their potential in mathematics, which would result in them passing one or more placement exams before their first semester. One of the principal requirements for preparing the class was to model it based on the syllabi of the UT math courses. Therefore, with help of the UT Mathematics Department, the syllabi of the impacted courses (Introductory Algebra with laboratory, Introductory Algebra, Intermediate Algebra, College Algebra, and Trigonometry and Analytical 
Geometry) were utilized for preparing the course. Also, available copies of old departmental exams were used to both determine the course content and as supplementary material.

In order to provide a more comprehensive experience for the students, different computer tools were also researched. Some requisites considered for selecting the product were that the software was available to the students online and throughout the day. Also, the software had to have the capability of helping out students in solving problems without giving away the answers. It was essential for the project that students had access to a tool permanently so they could work on their own schedule and receive some level of support if needed during irregular study hours.

The book utilized for preparing the course material was Matemáticas universitarias introductorias con nivelador MyMathLab (Introductory College Mathematics with MyMathLab Leveler, by Demana and Blitzer, 2009). This book was specially prepared to cover the essential mathematics topics needed for entry level college courses. Also, its content aligned well with UT mathematic courses requirements. The book was complemented with Pearson's MyMathLab online platform, which was an excellent tool for students to practice and work on their skills. The MyMathLab platform was perfectly aligned with the chosen book and it also had an electronic version of the book available at all times for the students.

During the 2013 summer, the improved tutoring sessions were conducted. For a total of 8 weeks, a 1 -week long intensive class was taught to students that had enrolled earlier. The class was free of charge and used the materials acquired by the project. Students were required to enroll previously for the week-long course and since the course was intensive and time sensitive, they were not allowed to enter the course mid-week. The independent study group was maintained because some students stated that they were not interested in a week-long class and only wanted to refresh specific concepts. Four (4) tutors and a graduate student that was already working with the project were hired for the 2013 summer session. They were divided into two (2) groups, the one that handled the class-like tutoring sessions and the one that worked with the independent study group. To comply with Human Resources regulations, tutors where assigned either morning or afternoon shifts. It was an unexpected, yet remarkable outcome that the tutors, out of their free will and commitment to both the project and the students, decided to stay the whole day with the students. This fact was one of the most important aspects of the success of the program.

The independent study group was maintained, but it quickly did not had as much impact as expected, since students gravitated towards the more familiar, class-like sessions. What quickly became evident to the tutors was that there were two distinct groups with different mathematic-level needs. Therefore, efforts were made to segregate the students according to their entry level mathematics course. One group was made of students that entered in both Introductory Algebra courses, while the other one grouped students that entered at a higher level (Trigonometry and Analytical Geometry). Also, the classes were adjusted to the separate levels to better fit the needs of the students in each group. The last weekly tutoring sessions were carried out following this structure and student feedback was very favorable with this approach.

\section{CONDITIONS OF THE TESTING FACILITIES: PAST AND PRESENT}

Placement exams are one of the tools utilized by UT to properly allocate new students in various disciplines, including mathematics. Since they are free and approving them results in receiving full credit for the corresponding course, they are an extremely powerful yet underutilized tool that entry-level students have. Placement exams were administered to students the same day that they visited the UT campus for admission. The mathematics placement exam is computer-based, and no resources besides pencils and papers are allowed. The students have to score 14 out of 20 questions correctly in order to pass an exam. It is noteworthy that this is a "Yes/No" proposition, meaning that the student has to solve perfectly each problem, as no partial credit is allowed. Because of lack of space, students usually take the placement exam in a back office that doubles as an examination center. The office partitions are not ceiling-high, meaning that environmental sounds from surrounding offices are heard in the examination site. Also, noises and distractions inherent from the traditional office work (phone, paperwork, etc.) are usually present at the time of examination. Realizing this, the Title V (Developing HispanicServing Institutions Program of the United States Department of Education) STEM UT project administrative staff 
coordinated with the Associate Vice-Chancellery for Retention to postpone the administration of the mathematics placement exam to SoE candidates. Also, the students are allowed whenever they pass an exam to leave and return later to take the next level exam, providing them with a chance to rest and prepare better for the next one.

\section{PROGRAM EVALUATION BY THE STUDENTS}

Participants of the SMTP were asked to fill out the same evaluation questionnaire that SoE students fill during their sessions. The 5-item questionnaire strives to capture the student feedback by using a 10-point Likert scale, where 10 and 0 were the highest and lowest scores possible, respectively. Table 1 presents the questions or statements presented to the 2012 summer students and their summarized answers.

Table 1: Student Evaluation Of The SMTP

\begin{tabular}{|c|c|c|}
\hline Question & Rate Ave. & Std. Dev. \\
\hline 1. How good do you consider the work of the tutor? & 9.74 & 0.80 \\
\hline 2. How do you rate the resources of the UT? & 9.35 & 1.18 \\
\hline 3. Please quantify your level of understanding of concepts prior consulting with the tutor: & 6.20 & 2.36 \\
\hline 4. Please quantify your level of understanding of concepts prior after the tutoring session: & 8.89 & 1.51 \\
\hline 5. Overall, how much you believe that the tutoring helped in your understanding of the concepts? & 9.47 & 0.95 \\
\hline
\end{tabular}

It can be appreciated from the overall results that the perception of students regarding the SMTP is a very positive one. It is noteworthy that the answers to questions 1,2 , and 5, which measure the student satisfaction with the process are above nine (9) with small standard deviations, which means answers where consistent. Question 3, which asks for perception of knowledge before the tutoring session took place, had a 6.2 average value, with a considerably large standard deviation. The large standard deviation suggests that their perception on previous knowledge is varied, but the prevalent consensus is that they feel that they are not prepared for college level engineering mathematics. This particular statistic is very relevant as it confirms the importance of extending this service to these students and the possibility to institutionalize this program once project funding is over.

\section{RESULTS}

During the 2011 summer, no tutoring sessions where offered. A total of 191 students went to take the placement exam. Of those, 8 backed out of the exam just before it. 183 students took exams, of which 26 approved one or more exams. In terms of exams taken, 207 exams where taken, with only 31 exams approved. These data is used as a baseline before the summer tutoring sessions where introduced.

During the 2012 summer, the first iteration of the summer SMTP took place. A total of 151 students went to take the placement exam, and of those, 36 students backed out of the exam just before taking it. 115 students took exams, for a total of 135 exams.

- No tutoring: 135 out of the 151 students did not take tutoring sessions. Of the 36 students that did not take the exam, 31 did not take tutoring sessions. Of the 115 students that took the exam, 104 did not take tutoring sessions. Of those 104, 18 students passed 1 or more exams, for a total of 21 exams passed.

- With tutoring: 16 out of the 151 students took tutoring sessions. Of the 36 students that did not take the exam, 5 took tutoring sessions. Of the 115 students that took the exam, 11 took tutoring sessions. Of those 11,5 students passed 1 or more exams, for a total of 6 exams passed.

During the 2013 summer, the renewed SMTP was implemented. A total of 135 students went to take the placement exam, and of those, 19 backed out of the exam just before taking it. 116 students took exams, for a total of 136 exams. 
- No tutoring: 45 out of the 135 students did not take tutoring sessions. Of the 19 students that did not take the exam, 13 did not take tutoring sessions. Of the 116 students that took the exam, 32 did not take tutoring sessions. Of those 32, 5 students passed 1 or more exams, for a total of 5 exams passed.

- With tutoring: 90 out of the 135 students took tutoring sessions. Of the 19 students that did not took the exam, 6 took tutoring sessions Of the 116 students that took the exam, 84 took tutoring sessions. Of those 84,36 students passed 1 or more exams, for a total of 44 exams passed.

\section{STATISTICAL ANALYSES}

\section{Statistical Analysis 1:}

In order to validate the effects that the program had over the passing rates of placement exams, a statistical analysis was performed. It was hypothesized that there should be a positive correlation between taking mathematics tutoring and passing one or more placement tests. Statistically significant results would provide evidence to conclude that the SMTP will continue to be effective in future years and that, if replicated elsewhere, the SMTP could lead to an improvement in mathematics placement exam results. Therefore, a Chi-Squared test for independence was performed to determine if there is a statistically significant association between tutoring and the passing rate in mathematics placement exams. As suggested by Greenwood (1996), Chi-Squared analyses are adaptable to testing multivariate distributions, thus providing an appropriate framework for analyzing the program's effects. The objective of presenting a high level of detail in this section is to have the paper also serve as a tutorial for readers who are unfamiliar with a Chi-Squared test of independence.

A Chi-Squared test compares two categorical variables. Categorical variables have a qualitative rather than quantitative nature; for example, male/female, pass/fail, cold/hot. The categorical variables may have more than two levels; for example, low/medium/high, North/South/East/West. Also, in some cases the qualitative variable may seem numerical but it is in reality qualitative in nature; for example, classifying values by year where each year is a number but serves as a qualifier. In addition, a numerical variable may be turned into a categorical variable by assigning ranges of values to particular levels; for example, the numerical values of a test may be turned into a pass/fail categorical variable. In fact, categorizing the mathematics placement exam results into pass/fail levels was done in this paper to perform the Chi-Squared test.

In a Chi-Squared test the researchers must decide on which of the two variables plays the role of the explanatory variable. In this paper the explanatory variable is "Tutoring", that is, whether the student participated in tutoring sessions or not. The other variable is known as the response variable. In this paper the response variable is the Exam Result divided into Pass/Fail categories. With this setup the results in the mathematics placement exam are explained by whether the student was tutored or not. The observed placement exam results for the years 20112013 are presented in Table 2 which is presented in the form required for a Chi-Squared test, that is, it includes the row and column sums. The table also includes the totals for the three-year period.

Table 2: Observed Placement Exam Results

\begin{tabular}{|l|c|c|c|}
\hline \multicolumn{1}{|c|}{$\mathbf{2 0 1 1}$} & Pass & Fail & Totals \\
\hline With Tutoring & 0 & 0 & 0 \\
\hline No Tutoring & 31 & 176 & 207 \\
\hline $\boldsymbol{\Sigma}$ & 31 & 176 & 207 \\
\hline
\end{tabular}

\begin{tabular}{|l|c|c|c|}
\hline \multicolumn{1}{|c|}{$\mathbf{2 0 1 3}$} & Pass & Fail & Totals \\
\hline With Tutoring & 44 & 60 & 104 \\
\hline No Tutoring & 5 & 27 & 32 \\
\hline$\Sigma$ & 49 & 87 & 136 \\
\hline
\end{tabular}

\begin{tabular}{|l|c|c|c|}
\hline \multicolumn{1}{|c|}{$\mathbf{2 0 1 2}$} & Pass & Fail & Totals \\
\hline With Tutoring & 6 & 9 & 15 \\
\hline No Tutoring & 21 & 99 & 120 \\
\hline $\boldsymbol{\Sigma}$ & 27 & 108 & 135 \\
\hline
\end{tabular}

\begin{tabular}{|l|c|c|c|}
\hline \multicolumn{1}{|c|}{ 11-13 Totals } & Pass & Fail & Totals \\
\hline With Tutoring & 50 & 69 & 119 \\
\hline No Tutoring & 57 & 302 & 359 \\
\hline $\mathbf{\Sigma}$ & $\mathbf{1 0 7}$ & $\mathbf{3 7 1}$ & $\mathbf{4 7 8}$ \\
\hline
\end{tabular}

Table 3 summarizes the conditional percentages from Table 2, that is, the percentages of the response variable (passed or failed the placement exam) for each value of the explanatory variable (tutored/not tutored). The table shows that a larger percentage of students who attended the tutoring sessions passed one of the mathematics placement exams. For example, looking at the totals (bottom of Table 3), $42 \%$ of the students who attended the 
tutoring sessions passed a placement exam. In contrast, only $15.9 \%$ of the students who were not tutored passed the placement exam. Similar results are shown for each individual year (note that tutoring started in 2012 so that the 2011 results only include students that were not tutored).

The results in Table 3 provide evidence to indicate that the tutoring sessions have been very effective and that tutoring is strongly related to passing a placement exam; however, these results by themselves are not enough to conclude that the relationship would hold in a larger population of students. This issue will be investigated further by establishing a hypothesis test. The results of the hypothesis test will establish if the evidence is strong enough to conclude, beyond a reasonable doubt, that the improvement in passing rates must be related to the tutoring sessions. If the evidence is not strong enough, then the results could be attributed to chance, i.e., sample variability, and not necessarily because a relationship exists between the two variables.

Table 3: Conditional Percentages Of Observed Counts

\begin{tabular}{|l|c|c|c|}
\hline \multicolumn{1}{|c|}{$\mathbf{2 0 1 1}$} & Pass & Fail & Totals \\
\hline With Tutoring & N/A & N/A & N/A \\
\hline No Tutoring & $31 / 207=15 \%$ & $176 / 207=85 \%$ & $207(100 \%)$ \\
\hline
\end{tabular}

\begin{tabular}{|l|c|c|c|}
\hline \multicolumn{1}{|c|}{$\mathbf{2 0 1 2}$} & Pass & Fail & Totals \\
\hline With Tutoring & $6 / 15=40 \%$ & $9 / 15=60 \%$ & $15(100 \%)$ \\
\hline No Tutoring & $21 / 120=17.5 \%$ & $99 / 120=82.5 \%$ & $120(100 \%)$ \\
\hline
\end{tabular}

\begin{tabular}{|l|c|c|c|}
\hline \multicolumn{1}{|c|}{$\mathbf{2 0 1 3}$} & Pass & Fail & Totals \\
\hline With Tutoring & $44 / 104=42.3 \%$ & $60 / 104=57.7 \%$ & $104(100 \%)$ \\
\hline No Tutoring & $5 / 32=15.6 \%$ & $27 / 32=84.4 \%$ & $32(100 \%)$ \\
\hline
\end{tabular}

\begin{tabular}{|l|c|c|c|}
\hline \multicolumn{1}{|c|}{ Totals } & Pass & Fail & Totals \\
\hline With Tutoring & $50 / 119=42 \%$ & $69 / 119=58 \%$ & $119(100 \%)$ \\
\hline No Tutoring & $57 / 359=15.9 \%$ & $302 / 359=84.1 \%$ & $359(100 \%)$ \\
\hline
\end{tabular}

$\mathbf{H}_{0}$ (Null Hypothesis): There is NO difference in placement exam passing rates between students who are tutored and those who are not, that is, the two variables are independent from each other.

$\mathbf{H}_{\mathbf{a}}$ (Alternate Hypothesis): There is a difference in placement exam passing rates between students who are tutored and those who are not, that is, that there is a relationship between the two variables (they are not independent). The null hypothesis in a Chi Square analysis implies that there are an equal proportion of students who passed the placement exams to those who did not pass.

To conduct the Chi Square test for independence it is necessary to calculate a new set of counts - the Expected Counts - which is based on the premise that the two variables are independent from each other, that is, assuming that the null hypothesis was true. The expected count essentially asks the following question: how many students would be expected to pass the exam if there was no relationship between tutoring and passing rates?

Since the expected counts are based on the assumption that the two variables are independent, as established by the null hypothesis, then we may use the basic probability rule that states that "the probability that two events $A$ and $B$ will occur is the product of their individual probabilities, or $P(A$ and $B)=P(A) * P(B)$ ". By following this simple rule on each of the four cells of the table, the expected counts can be calculated.

The following example illustrates the calculation for the top-left cell of the table of totals. For the top-left cell, $\mathrm{A}=$ "Passed the exam" and B = "with tutoring". The calculation for the individual probability uses a row or a column sum and divides it by " $n$ ", the number of examinees. 
The computation of expected count for top-left cell of the table of totals is as follows:

$$
\begin{aligned}
& \mathrm{P}(\mathrm{A} \text { and } \mathrm{B})=\mathrm{P}(\text { Passed the Exam and was tutored })=\mathrm{P}(\text { Passed the Exam }) * \mathrm{P}(\text { Tutored }) \\
& \mathrm{P}(\mathrm{B})=\mathrm{P}(\text { Passed the Exam })=107 / 478=22.38 \% \\
& \mathrm{P}(\mathrm{B})=\mathrm{P}(\text { Tutored })=119 / 478=24.9 \% \\
& \mathrm{P}(\mathrm{A} \text { and } \mathrm{B})=(107 / 478) *(119 / 478)=5.57 \%
\end{aligned}
$$

Since there were a total of 478 examinees, if passing the exam and tutoring were independent of each other, then the count of examinees passing the exam with tutoring would be expected to be:

Examinees Total $* \mathrm{P}($ Passed the Exam with Tutoring $)=478 *(107 / 478) *(119 / 478)=27$

The same procedure can be carried out for each of the remaining three cells:

Examinees Total $* \mathrm{P}($ Passed the Exam with no Tutoring $)=478 *(107 / 478)(359 / 478)=80$

Examinees Total $* \mathrm{P}($ Failed the Exam with Tutoring $)=478 *(371 / 478)(119 / 478)=92$

Examinees Total $* \mathrm{P}($ Failed the Exam with no Tutoring $)=478 *(371 / 478)(359 / 478)=279$

Check the sum of expected counts: $27+80+92+279=478$ (ok)

\begin{tabular}{|l|c|c|c|}
\hline \multicolumn{1}{|c|}{ Totals } & Pass & Fail & Totals \\
\hline $\mathbf{2 0 1 1 - 1 3}$ & 50 & 69 & 119 \\
\hline With Tutoring & 57 & 302 & 359 \\
\hline $\boldsymbol{\Sigma}$ & 107 & 371 & 478 \\
\hline
\end{tabular}

The Chi Square test measures how far the expected counts are from the observed ones and the conclusion is based on the size of the discrepancy between them as formulated below:

$$
x^{2}=\sum_{\text {all cells }} \frac{(\text { Observed Count }- \text { Expected Count })^{2}}{\text { Expected Count }}
$$

Table 4: Observed And Expected Counts. Expected Counts In Parentheses

\begin{tabular}{|l|c|c|c|}
\hline \multicolumn{1}{|c|}{ Totals } & Pass & Fail & Totals \\
\hline $\mathbf{2 0 1 1 - 1 3}$ & $50(27)$ & $69(92)$ & 119 \\
\hline With Tutoring & $57(80)$ & $302(279)$ & 359 \\
\hline $\boldsymbol{\Sigma}$ & 107 & 371 & 478 \\
\hline
\end{tabular}

The discrepancy between observed and expected counts, as measured with the Chi-Squared statistic, is considered "large" (statistically significant) if it is greater than 3.84 for a $2 \times 2$ case. This corresponds to a significance level of $95 \%$. The corresponding minimum $p$-value $=1.0-0.95=0.05$. The smaller the $p$-value, the more likely it is that there is an association between the variables.

For this case, the Chi Square statistic is

$\mathrm{X}^{2}=(50-27)^{2} / 27+(57-80)^{2} / 80+(69-92)^{2} / 92+(302-279)^{2} / 279$

$X^{2}=19.6+6.6+5.7+1.9$

$\mathrm{X}^{2}=33.8$

Since the value $X^{2}=33.8$ is much larger than the required cutoff $X^{2}=3.84$ for a $2 \times 2$ case, the conclusion is that the results are statistically significant.

The problem has also been solved using the $\mathrm{R}$ programming language for more precise results. The $X^{2}$ result (35.14) calculated by $\mathrm{R}$ is slightly higher than the result calculated manually (33.8). This is due to round-off errors during the manual calculation which rounded the "expected counts" to the nearest integer. R also computes 
the p-value and it shows that it is smaller than $3.056 \times 10^{-9}$ which is much lower than the minimum required (pvalue $)_{\min }=0.05$.

The chi square test for independence clearly shows that the null hypothesis can be rejected, i.e., that the two variables (tutoring and passing rates) are not independent from each other. Therefore, the alternate hypothesis is accepted. It may be concluded that there is a statistically significant association between receiving tutoring and the passing rates in the placement exam. The results provide evidence that the improved passing rates in mathematics placement exams will continue if the tutoring sessions continue in the future or, if the tutoring sessions are replicated elsewhere (another university or program).

\section{Statistical Analysis 2:}

A second Chi-Squared test for independence was conducted to determine if there was any association between the year that the mathematics placement test was taken (explanatory variable) and the passing rate for students that were not tutored (response variable). If there is no association - which is the expectation - the result may be generalized into the past and the future (entire population), i.e., when there is no tutoring, the passing rates in the mathematics placement exams will be low irrespective of the year the exam is taken.

Table 5 contains the observed counts, and the row and column sums. Table 6 contains the conditional percentages of the observed counts. Table 7 contains the expected counts. The procedure to obtain the percentages and the expected counts is the same one carried out previously. In this case, the matrix has 3 rows (three years) and 2 rows (pass, fail).

Table 5: Observed Counts Per Year (Only For Cases With No Tutoring)

\begin{tabular}{|l|c|c|c|}
\multicolumn{1}{c|}{} & Pass & Fail & \multicolumn{1}{c|}{} \\
\hline $\mathbf{2 0 1 1}$ (No tutoring) & 31 & 176 & 207 \\
\hline $\mathbf{2 0 1 2}$ (No tutoring) & 21 & 99 & 120 \\
\hline $\mathbf{2 0 1 3}$ (No tutoring) & 5 & 27 & 32 \\
\hline Sum & 57 & 302 & 359 \\
\hline
\end{tabular}

Table 6: Conditional Percentages Of The Observed Counts (Only For Cases With No Tutoring)

\begin{tabular}{|c|c|c|c|}
\hline & Pass & Fail & $\Sigma$ \\
\hline 2011 (No tutoring) & $31 / 207=15 \%$ & $176 / 207=85 \%$ & (207) $100 \%$ \\
\hline 2012 (No tutoring) & $21 / 120=17.5 \%$ & $99 / 120=82.5 \%$ & (120) $100 \%$ \\
\hline 2013 (No tutoring) & $5 / 32=15.6 \%$ & $27 / 32=84.4 \%$ & (32) $100 \%$ \\
\hline
\end{tabular}

Table 7: Observed And Expected Counts. Expected Counts In Parentheses. (No Tutoring Only)

\begin{tabular}{|l|c|c|c|}
\cline { 2 - 4 } \multicolumn{1}{c|}{} & Pass & Fail & \multicolumn{1}{c|}{} \\
\hline $\mathbf{2 0 1 1}$ (No tutoring) & $31(32.87)$ & $176(174.13)$ & 207 \\
\hline $\mathbf{2 0 1 3}$ (No tutoring) & $21(19.05)$ & $99(100.95)$ & 120 \\
\hline Sum & $5(5.08)$ & $27(26.92)$ & 32 \\
\hline
\end{tabular}

The conditional percentages in Table 6 are very close to each other. So are the observed and expected counts in Table 7. Since the $X^{2}$ statistic measures the difference between the observed and the expected counts it is expected to have a low value of the test statistic $X^{2}$. The hypothesis test for this case is defined as follows:

$\mathbf{H}_{\mathbf{0}}$ (Null Hypothesis): There is NO difference in placement exam passing rates from year to year for the three years that data is available $(2011,2012,2013)$; therefore, the two variables are independent from each other.

$\mathbf{H}_{\mathbf{a}}$ (Alternate Hypothesis): There is a difference in placement exam passing rates from year to year, that is, that there is a relationship between the two variables (so that they are not independent). 
The chi square analysis was also run in the $\mathrm{R}$ programming language. The $X^{2}$ statistic calculated by $\mathrm{R}\left(X^{2}=\right.$ 0.364 ), as expected, is very low. For a $3 \times 2$ matrix the minimum required value to show association at a $95 \%$ significance level is $X^{2}=5.991$. In addition, the p-value calculated by $\mathrm{R}$ is 0.8336 which is considerably higher than the minimum required $\mathrm{p}$-value $(0.05)$.

Therefore, the null hypothesis is accepted.

By accepting the null hypothesis, the implication is that, when there is no tutoring, the passing rates in the mathematics placement exams will be low (approximately a 15\% passing rate) irrespective of the year the exam is taken.

This result may be generalized into the past and the future (entire population). When looking into the past, this Chi-Squared test has established that there is no need to gather and analyze additional data from previous years as it will most probably be near $15 \%$. When looking into the future, this Chi-Squared test has established that, if the SMTP were to be eliminated, the passing rates in the future would fall once again to the $15 \%$ level. This conclusion provides a solid and statistically-significant basis to institutionalize the SMTP after the grant ends in 2016.

\section{CONCLUSIONS AND RECOMMENDATIONS}

After successfully implementing the SMTP for two years, some conclusions can be drawn:

1. The SMTP has shown to be statistically significant in helping students pass one or more placement exams in UT.

2. Freshmen students showed high compromise and engagement with the SoE during this period.

3. The program primes the SoE freshmen to additional types of supplementary instruction beyond classic lectures.

4. The improvements made for the second year of the program made it highly successful.

5. Reception was very favorable amongst freshmen students and their families.

6. Program promotes the integration between students before they begin their first semester in the UT.

7. Fear of entering into an advanced course that they will fail was one of the reasons for not taking the placement exam.

Some recommendations for improving this program or any similar program that wants to replicate it are:

1. Although many students participated in the SMTP (sometimes for more than a week), not everyone took the placement exam. Efforts should also focus in getting students to understand the benefit they can reap from taking the placement exam.

2. Implement a similar program during the August/December semester for students that want to enroll in semesters that start in January.

3. Divide students from the start into groups depending on their mathematics entry level.

4. Maintain close communications with the tutors in order to detect more room for improvement.

\section{ACKNOWLEDGEMENTS}

This project was funded by the United States Department of Education Title V grant (\#P031C110050 - Increasing graduation rates of Hispanic engineering students by achieving deep learning of concepts). It is noteworthy that a substantial part of the success of the SMTP was due to the immense dedication and sense of responsibility that the tutors showed towards the program. Mr. Gelson Díaz, Miss Brenda L. Morales, Miss Christina De Freitas, Mr. Pedro Bernabe (undergraduate students of the SoE), Mr. Miguel Delgado and Mr. Jorge Jimenez (graduate students of the SoE), and Mr. Charles Rosa (SoE graduate) were instrumental in engaging the students and achieving the program's goals. Also, special thanks are due to Mrs. Luz Vilches, M.A. Engineering Student Services Office Director, and Mr. Fernando Acosta, M.B.A. and Mrs. Elizabeth Colón, B.A former and current Engineering Student Services Office Coordinator, respectively. They were instrumental in the implementation and success of the project. 


\section{AUTHOR INFORMATION}

Dr. Rolando García-González, P.E., is an assistant professor of the School of Engineering at Universidad del Turabo (UT) at Puerto Rico. He is currently Title V STEM Grant Director. He received his PhD in civil engineering in 2007 from the Universidad de Puerto Rico at Mayagüez. He joined the Engineering Department at UT in January 2011. Prior to that, being a licensed professional engineer in Puerto Rico, he worked as a structural engineering consultant in multiple projects and as an instructor at Caribbean University in Bayamón. His research interests include engineering education and seismic retrofitting of reinforced concrete structures.

E-mail: rogarcia@suagm.edu (Corresponding author)

Dr. Juan C. Morales, P.E., joined the Mechanical Engineering Department at Universidad del Turabo in 1995. He holds the rank of Professor. He has been Department Head since 2003. He served as the ABET Coordinator of the School of Engineering between 2003 and 2010. As ABET Coordinator, Dr. Morales had the privilege of working closely with the entire engineering faculty in the process of establishing a systemic and sustainable Outcomes Assessment Program. He coordinated the effort to obtain the initial ABET accreditation (EAC) for all four engineering programs. His current research explores innovations in the classroom and their diffusion.

E-mail: jcmorales@ suagm.edu

Mrs. Gloribel Rivera-Martínez, M.B.A., is the coordinator of the Title V STEM Grant of the School of Engineering at Universidad del Turabo. She received her BA and MBA degrees in Management and Material Control from Universidad del Turabo. She has ample experience in this field, working over 12 years as coordinator and interim director of various projects that included student development components, such as VISION - MASTT / NASA \& GEAR UP projects.

E-mail: glrivera@suagm.edu

\section{REFERENCES}

1. Atkinson, R. K., Renkl, A., \& Merrill, M. M. (2003). Transitioning From Studying Examples to Solving Problems: Effects of Self-Explanation Prompts and Fading Worked-Out Steps. Journal of Educational Psychology, 95(4), 774.

2. Beasley, C.J. (1997). Students as teachers: The benefits of peer tutoring. In R. Pospisil \& L.Willcoxson (Eds), Learning Through Teaching: Proceedings of the 6th Annual Teaching Learning Forum. (pp. 21-30). Perth, 5-6 February. [last viewed February 19, 2014] http://otl.curtin.edu.au/professional_development/conferences/tlf/tlf1997/beasley.html

3. Boud, D., Cohen, R., \& Sampson, J. (2001). Peer learning in higher education: learning from \& with each other. Psychology Press.

4. Bowen, E., Prior, J., Lloyd, S., Thomas, S., \& Newman-Ford, L. (2007). Engineering more engineersbridging the mathematics and careers advice gap. engineering education, 2(1), 23-32.

5. Chen, C., \& Liu, C. C. (2011). A case study of peer tutoring program in higher education. Research in Higher Education Journal, 11. 1-10. [last viewed May 19, 2014] http://www.ww.aabri.com/ manuscripts/11757.pdf

6. Davis, C., \& Wilcock, E. (2004). Case studies in engineering. Effective learning and teaching in engineering, 51-71.

7. Farkas, G. (2003). Racial disparities and discrimination in education: What do we know, how do we know it, and what do we need to know?. The Teachers College Record, 105(6), 1119-1146.

8. $\quad$ Greenwood, P. E. (1996). A guide to chi-squared testing (Vol. 280). John Wiley \& Sons.

9. Henderson, N., Fadali, M. S., \& Johnson, J. (2002, November). An investigation of first-year engineering students' attitude toward peer-tutoring. In Frontiers in Education, 2002. FIE 2002. 32nd Annual (Vol. 2, pp. F3B-1). IEEE.

10. Knight, D. W., Carlson, L. E., \& Sullivan, J. F. (2003, June). Staying in engineering: Impact of a hands-on, team-based, first-year projects course on student retention. In CD) Proceedings, ASEE Conference and Exhibition.

11. Krause, K. L., \& Coates, H. (2008). Students' engagement in first- year university. Assessment \& Evaluation in Higher Education, 33(5), 493-505. 
12. Luca, J., \& Clarkson, B. (2002). Promoting students learning through peer tutoring - A case study. Paper presented at the ED-MEDIA World Conference on Educational Multimedia, Hypermedia and Telecommunications, Denver, CO. (ERIC Document Reproduction Service No. ED477058)

13. Magin, D. J., \& Churches, A. E. (1995). Peer tutoring in engineering design: A case study. Studies in Higher Education, 20(1), 73-85.

14. Newman-Ford, L., Lloyd, S., \& Thomas, S. (2007). Evaluating the performance of engineering undergraduates who entered without A-level mathematics via a specialist six-week "bridging technology" programme. engineering education, 2(2), 33-43.

15. Power, C., \& Dunphy, K. (2010). Peer facilitated learning in Mathematics for Engineering: a case study from an Australian university. Engineering Education, 5(1), 75-84.

16. Roscoe, R. D., \& Chi, M. T. (2008). Tutor learning: The role of explaining and responding to questions. Instructional Science, 36(4), 321-350.

17. Tinto, V. (2006) Research and practice of student retention: what next?" Journal of College Student Retention: Research, Theory, and Practice, 8, (1) 1-20. 